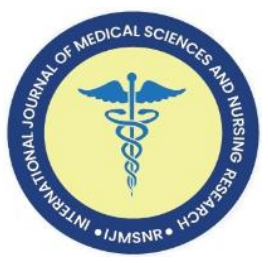

\title{
Blood transfusion incidence in primary Total Knee Arthroplasty of Unilateral vs Bilateral group with high prevalence of low haemoglobin concentration: A Retrospective Observational Study
}

Jai Thilak Kailathuvalapil ${ }^{1}$, Madhusudhan Tammanaiah ${ }^{2}$ (D) , Nabeel Mohamed Therakka Parambil ${ }^{3}$, Sujith Paliath

Shaju $^{4}$, Senthilvel Vasudevan ${ }^{5}$

1, 2, 3, ${ }^{4}$ Department of Orthopaedics, Amrita Institute of Medical Sciences, Amrita Vishwa Vidyapeetham, Kochi, Kerala, India. ${ }^{5}$ Assistant Professor of Statistics, Department of Pharmacy Practice, College of Pharmacy, King Saud Bin Abdulaziz University for Health Science, Riyadh, Saudi Arabia.

\section{Abstract}

Background: Blood transfusion is one of the major concerns following Total Knee Arthroplasty (TKA). We assessed the incidence rate of blood transfusion (packed red cells) in our geographical group based on age, gender, preoperative haemoglobin(Hgb) and following both unilateral and bilateral primary TKA done either in single stage or sequentially after a week.

Materials and Methods: This was a retrospective observational study which included 200 patients who underwent primary TKA unilateral, bilateral done in single stage and sequential from June 2015 to May 2016. Two doses of parenteral Tranexamic acid and periarticular cocktail injection given. Transfusion was indicated with postoperative Hgb below $8 \mathrm{~g} / \mathrm{dl}$ associated with or without clinical signs of tissue hypoperfusion.

Results: The study group was 200 patients with age group of 50-81 years, of which $154(77 \%)$ were female and $46(23 \%)$ were male and had a mean preoperative Hgb level of $12.6 \mathrm{~g} / \mathrm{dl} .88(44 \%)$ unilateral, $40(20 \%)$ bilateral and $72(36 \%)$ sequential TKA were performed and 7 $(7.95 \%), 12(30 \%)$ and $26(36 \%)$ patients received blood transfusion respectively. Among the transfused 45 patients, 38 patients were bilateral group, of which $30(66.6 \%)$ patients had a preoperative Hgb levels of 10-12 g/dl, indicating high incidence of transfusion in bilateral cases compared to unilateral and with preoperative $\mathrm{Hgb}$ levels of $10-12 \mathrm{~g} / \mathrm{dl}$ which was statistically significant with $\mathrm{p}$-value $<0.05$.

Conclusion: In our study, age and gender were not the major factors for blood transfusion, but low preoperative Hgb levels and bilateral single stage and sequential TKA showed significantly higher incidence of blood transfusion.

Keywords: total knee arthroplasty, blood transfusion, preoperative Hgb

Article Summary: Submitted: 10-July-2021 Revised: 28-August-2021 Accepted: 05-September-2021 Published: 30-September-2021

\begin{tabular}{|c|c|c|}
\hline Quick Response Code: & \multirow{3}{*}{$\begin{array}{l}\text { Web Site } \\
\text { p://ijmsnr.com/ }\end{array}$} & \multirow[b]{2}{*}{$\begin{array}{l}\text { This is an open access journal, and articles are distributed under the terms of the } \\
\text { Creative Commons Attribution-Non-Commercial-ShareAlike } 4.0 \text { International } \\
\text { License, which allows others to remix, tweak, and build upon the work } \\
\text { non-commercially, as long as appropriate credit is given and the new creations } \\
\text { are licensed under the identical terms. }\end{array}$} \\
\hline & & \\
\hline & & $\begin{array}{r}\begin{array}{r}\text { Corresponding Author: Dr. Madhusudhan Tammanaiah, } \\
\text { Consultant Orthopaedic Surgeon, Kamakshi Hospital, } \\
\text { Mysore, Karnataka, India. }\end{array} \\
\text { Email ID: madhusudhan.doc@gmail.com Cell No: +918333873990 }\end{array}$ \\
\hline
\end{tabular}

\section{Introduction}

Total knee arthroplasty (TKA) is an elective procedure widely used for treating osteoarthritis of knee which is a disease of inflammatory and degenerative nature that causes knee joint cartilage destruction leading to pain and variable deformities. It is one of the most common procedures performed in the orthopedic department in recent years. The frequency of TKA has shown a growth projection of $601 \%$ between 2005 and 2030. [1] Like other major surgeries, there are several complications also noticed during and after TKA such as persistent knee pain, stiffness, blood loss and thromboembolism. [2-4] The bleeding is mainly noticed after release of the tourniquet. [5] The amount of blood loss is variable and sometimes it leads to scenarios where blood transfusion becomes inevitable. [6] Surgical blood loss and transfusion is a concern for both patients and surgeons despite advances in blood conservation techniques. While the popularity of preoperative autologous donation has declined for logistical reasons, erythropoietin (EPO) and perioperative autologous blood salvage strategies have increased in popularity. [7] Still, homologous blood transfusion remains the gold-standard approach for increasing blood cell count in anaemic patients in the perioperative period.

An incidence rates of 9-84\% blood transfusion have been reported following TKA [8] and several factors were found associated with increased risk of blood transfusion which includes patient related factors like gender, body mass index (BMI), preoperative haemoglobin $(\mathrm{Hgb})$ level, American Society of Anesthesiologists (ASA) score, and associated medical comorbidities and surgery related factors like

How to cite this article: Kailathuvalapil JT, Tammanaiah M, Parambil NMT, Shaju SP, Vasudevan S. Blood transfusion incidence in primary Total Knee Arthroplasty of Unilateralvs Bilateral group with high prevalence of low haemoglobin concentration. Int J Med Sci and Nurs Res 2021;1(1):8-11. 
operation time, technique, usage of tourniquet and amount of blood loss during perioperative period. [9-12] Though blood transfusion is lifesaving, it is associated with several complications such as hemolytic reactions, transfusion-related lung injury (TRALI), transmission of infectious pathogens and overall high risk of morbidity and mortality. [13, 14] The aim of this study is to fill the knowledge gap on blood transfusion (packed red cells) following TKA in a variant geographical and ethnic group by estimating its incidence rate based on demographic parameters such as age, gender, preoperative $\mathrm{Hgb}$ and following both unilateral and bilateral TKA done either in single stage or sequentially.

\section{Materials and Methods:}

This is a retrospective observational study which includes 200 patients who underwent primary TKA - unilateral, bilateral single stage, bilateral sequential (one week apart) from June 2015 to May 2016. Patients with coagulation disorders, thrombocytopenia, disturbances of platelet function, or other hematological diseases were excluded from the study. Gender, age, preoperative Hgb, unilateral, bilateral(single stage and sequential) were evaluated for their relationship to blood transfusion in the perioperative period. All TKA were performed by a single senior arthroplasty surgeon. All patients received intravenous tranexamic acid $1 \mathrm{gm}$ before incision and 4 hours after the surgery unless contraindicated. Tourniquet was used at the time of exposure and cementation only. Periarticular cocktail injection of $30 \mathrm{ml}$ consisting of Bupivacaine, Morphine, epinephrine, antibiotics diluted in normal saline given for all patients. Drain was not used, and compression bandage was applied for adequate tamponade. Hgb levels assessed in the post-anesthesia care unit on postoperative day-1. The trigger for bloodtransfusion was $\mathrm{Hgb} \leq 8 \mathrm{~g} / \mathrm{dl}$ with or without presence of symptoms of tissue hypoperfusion. [15] In patients undergoing sequential TKA, subcutaneous Enoxaparin sodium was given in the interimperiod between the two surgeries and stopped the day prior. Aspirin orally was given in all patientsas DVT prophylaxis for a period of 4 weeks.

Statistical analysis: All data were procured retrospectively from a prospectively maintained electronic database (AHMS version 6.0.7) by an independent investigator not involved in the surgery. Institutional review board (IRB) approval was taken. Results were analyzed using SPSS 20.0 version. Quantitative data were expressed as the mean \pm SD. Categorical data were analyzed with Chi-Square test / Fisher's Exact test wherever applicable. p-value less than 0.05 was considered as statistically significant.

\section{Results}

221 patients underwent TKA from June 2015 to May 2016, of which 21 $(9.5 \%)$ patients were excluded from the study (Revision TKA, coagulation disorders). Of the 200 patients, 46 (23\%) were males and $154(77 \%)$ were females. $88(44 \%), 40(20 \%)$ and $72(36 \%)$ patients underwent unilateral, bilateral (single stage) and sequential TKA respectively. Mean preoperative $\mathrm{Hgb}$ was $12.6 \mathrm{~g} / \mathrm{dl}$ with overall incidence of blood transfusion in 45 (22.5\%) patients and mean postoperative $\mathrm{Hgb}$ level with or without transfusion was $11.28 \mathrm{~g} / \mathrm{dl}$.

Age: To analyze the relationship between age and incidence of blood transfusion, patients were divided into two age groups, 94 (47\%) patients with age less than 65 and $106(53 \%)$ patients with age more than 65, of which $20(21 \%)$ patients and $25(23.5 \%)$ patients were transfused respectively. No statistically significant relationship between age and blood transfusion noted with p-value 0.696. Gender: Out of 154 females and 46 males, 37 (24\%) patients \& 8 (17\%) patients received blood transfusion respectively. And the relationship between gender and blood transfusion in TKA was not statistically significant with pvalue 0.231 .

Unilateral / Bilateral / Sequential: Out of 200 TKA performed, 88 (44\%) unilateral, $40(20 \%)$ bilateral single stage and $72(36 \%)$ sequential TKA.Among them, 7 (7.95\%), $12(30 \%)$ and $26(36 \%)$ patients received blood transfusion respectively. Patients who underwent bilateral single stage and sequential TKA received high blood transfusion in comparison to unilateral TKA, which was statistically highly significant with p-value $<0.0001$.

Relation to preoperative Hgb: On further evaluation, the need of blood transfusion based on preoperative $\mathrm{Hgb}$ was classified under 10 $12 \mathrm{~g} / \mathrm{dl}$ and $>12 \mathrm{~g} / \mathrm{dl} .101$ patients $(50.5 \%)$ had preoperative Hgb level of $10-12 \mathrm{~g} / \mathrm{dl}$ and 99 patients $(49.5 \%)>12 \mathrm{~g} / \mathrm{dl} .45$ (22.5\%) patients were transfused and of which $30(66.6 \%)$ patients had preoperative $\mathrm{Hgb}$ levels of $10-12 \mathrm{~g} / \mathrm{dl}$. In unilateral and bilateral single stage TKA the incidence of blood transfusion in patients with $10-12 \mathrm{~g} / \mathrm{dl}$ didn't show statistical significance with p-value 0.676 and 0.494 respectively whereas in sequential TKA statistical significance noted with p-value 0.027 . Overall transfusion rate in patients with preoperative $\mathrm{Hgb}$ levels of $10-12 \mathrm{~g} / \mathrm{dl}$ was high and results were statistically significant with p-value $0.019(<0.05)$ as shown Figure-1.

Figure 1. Chart showing incidence of blood transfusion with variable preoperative $\mathrm{Hgb}$ levelsin unilateral/ bilateral/sequential TKA patients.

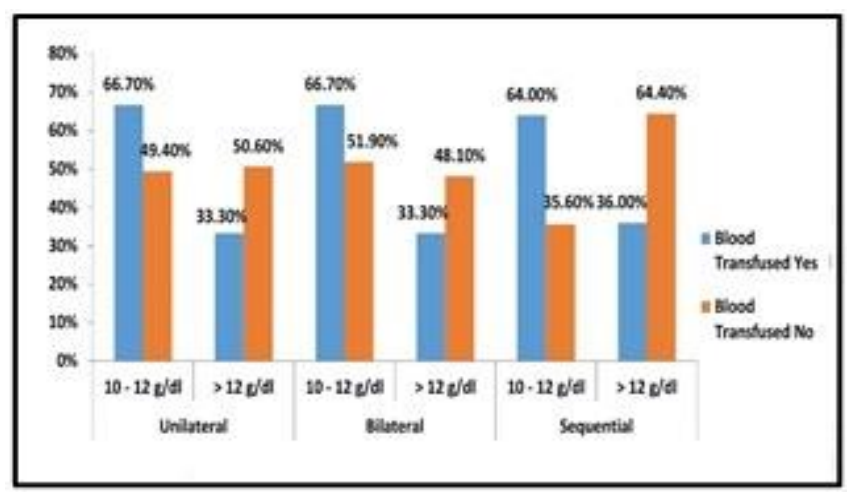

\section{Discussion}

Blood loss during total knee arthroplasty is variable. Several studies didn't consider "hidden" blood loss, including loss due to extravasation into the tissues; residual blood in the joint; and loss due to hemolysis, hematoma formation, or bleeding around the prosthesis for assessment of actual blood loss during the surgery. The inability to predict the need for transfusion in these patients has clinically and economically important consequences. During unpredicted clinical scenarios, patients often receive allogeneic blood which increases the risk of allergic reactions, transmission of infectious agents, and 
immunomodulatory effects. Beirbaum et al [16] reported rates of $39 \%$ of TKA patients received transfusion and, in our study, the mean incidence of blood transfusion was $22.5 \%$. There was no statistically significant relationship in specific age groups or gender who were transfused in unilateral or bilateral TKA. In one of the recent studies by Abdullah A. AlTurkiet al [17] conducted in a tertiary care centre, Riyadh, Saudi showed high incidence of blood transfusion in older females with high BMI. In our study BMI was not included.

Beirbaum et al [16] prospectively evaluated the need for autologous or homologous blood transfusion in patients undergoing both Total hip arthroplasty and Total Knee arthroplasty based on preoperative Hgb level and found that patients with $\mathrm{Hgb}$ level less than $13 \mathrm{gm} / \mathrm{dl}$, particularly 10 $13 \mathrm{~g} / \mathrm{dl}$ needed transfusion. Gerardo Alvarez-Uria et al [18] analyzed the prevalence of anemia in our geographical area and noted a mean haemoglobin concentration of $11.3 \mathrm{~g} / \mathrm{dl}$. In our study group also $>50 \%$ of patients had preoperative Hgb levels of $10-12 \mathrm{~g} / \mathrm{dl}$ and in turn the need for blood transfusion was high. David W. Fabi et al [19] retrospectively analyzed the complications rate of unilateral TKA and bilateral simultaneous TKA and found 4 times higher rate of single stage or sequential compared to unilateral TKA, blood transfusion in bilateral simultaneous TKA. In our study cohort also, blood transfusion rate was high in bilateral TKA done either single stage or sequential compared to unilateral TKA.

Joshua B. Holt et al [20] conducted a prospective study in which 488 patients underwent primary TKA with a multimodal, multidisciplinary approach to perioperative blood loss management and in turn reducing the blood transfusion which included preoperative hemoglobin optimization, minimization of perioperative blood loss and evidence-based transfusion guidelines. This approach was also substantiated by Sara Moráis et al [21] which also included femoral canal obturation; peri and intra-articular cocktail injection; and two doses of parenteral tranexamic acid (TXA). In our study group we also followed many of these protocols for reducing blood loss.

Complications like blood borne disease, allergic reaction, immunomodulatory reactions, post-operative infection, DVT post transfusion were also observed in the study group. Nicholas B. Frisch et al [22] reported DVT rate of $1.99 \%$ and deep surgical site infection (DSSI) rates of statistically higher in the transfused patients. Bierbaum et al [16] reported infection rates of $7 \%$ in transfused patients. But no such complications noted in our transfused patients. Though DVT prophylaxis was given in all patients, assessment of DVT in the form of ultrasound doppler was done only in symptomatic patients. Hence actual incidence of DVT or pulmonary embolism in asymptomatic patients not assessed.

\section{Conclusion}

In conclusion age and gender variability were not the major confounding factors for blood transfusion but low preoperative Hgb levels in between $10-12 \mathrm{~g} / \mathrm{dl}$ found in above half of our geographic population had increased incidence of blood transfusion. In comparison with unilateral vs bilateral, bilateral TKA done either single stage or sequential showed a higher incidence of blood transfusion and more significantly in the group with $\mathrm{Hgb}$ $10-12 \mathrm{~g} / \mathrm{dl}$.

Acknowledgement: The authors thank the participants, members of the Department of Orthopaedics and Anesthesia, Operation Theatre and Nursing staff for co-operating throughout the study period.
Authors Contributions: JTK, MT: Conception and design. JTK, MT, SPS: Acquisition of Data. SV, MT: Analysis and Interpretation of data. All authors-JTK, MT, NMTP, SPS, and SV: Drafting the article, revising it for Intellectual content. All authors were checked and approved of the final version of the manuscript.

Here, JTK-Jai Thilak Kailathuvalapil, MT-Madhusudhan Tammanaiah, NMTP-Nabeel Mohamed Therakka Parambil, SPSSujith Paliath Shaju and SV-Senthilvel Vasudevan.

Source of funding: We didn't get any types of financial support from our parent institution and any other financial organization.

Conflict of Interest: The authors declared no conflict of interest

\section{References:}

1. Kurtz S, Ong K, Lau E, Mowat F, Halpern M. Projections of primary and revision hip and knee arthroplastyin the United States from 2005 to 2030. J Bone Joint Surg 2007; 89(4):780-785. PMID: 17403800

2. Beswick AD, Wylde V, Gooberman-Hill R, Blom A, Dieppe P. What proportion of patientsreport long-term pain after total hip or knee replacement for osteoarthritis? A systematic review of prospective studies in unselected patients. BMJ Open 2012;2(1): e000435. PMID: 22357571

3. Januel JM, Chen G, Ruffieux C, Quan H, Douketis JD, Crowther MA, et al. Symptomatic in-hospital deep vein thrombosis and pulmonary embolism following hip and knee arthroplasty among patients receiving recommended prophylaxis: a systematic review. JAMA 2012; 307(3): 294-303. PMID: 22253396

4. Ritter MA, Harty LD, Davis KE, Meding JB, Berend ME. Predicting range of motion after total knee arthroplasty. Clustering, log-linear regression, and regression tree analysis. J Bone Joint Surg Am 2003; 85(7): 1278-1285. PMID:12851353

5. Burke DW, O'Flynn H. Primary total knee arthroplasty. In: Chapman MW, editor. Chapman's orthopedic surgery: $3^{\text {rd }}$ edition. Lippincott Williams \& Wilkins; Philadelphia: 2001:2870-2895.

6. Lotke PA, Faralli VJ, Orenstein EM, Ecker ML. Blood loss after total knee replacement. Effects of tourniquet release and continuous passive motion. J Bone Joint Surg Am. 1991; 73(7):1037-1040. PMID: 1874765

7. So-Osman C, Nelissen RGHH, Koopman-van Gemert AWMM, Kluyver E, Pöll RG, Onstenk R et al. Patient blood management in elective total hip and knee-replacement surgery (Part 1): A randomized controlled trial on erythropoietin and blood salvage as transfusion alternatives using a restrictive transfusion policy in erythropoietin-eligible patients. Anesthesiology 2014; 120(4):839-851. PMID: 24424070

8. Barr PJ, Donnelly M, Cardwell C, Alam SS, Morris K, Parker M, et. al. Driversof transfusion decision making and quality of the evidence in orthopedic surgery: a systematic review of the literature. Transfus Med Rev 2011;25(4):304-316. PMID: 21640550

9. Maxwell MJ, Wilson MJA. Complications of blood transfusion. Continuing Education in Anaesthesia Critical Care \& Pain 2006; 6(6):225-229. https://doi.org/10.1093/bjaceaccp/mk1053 
10. Rawn J. The silent risks of blood transfusion. Curr Opin Anaesthesiol 2008;21(5):664-668. PMID: 18784496

11. Park JH, Rasouli MR, Mortazavi SM, Tokarski AT, Maltenfort MG, Parvizi J. Predictors of perioperative blood loss in total joint arthroplasty. J Bone Joint Surg Am 2013;95(19):1777-1783.

PMID: 24088970

12. Carling MS, Jeppsson A, Eriksson BI, Brisby H. Transfusions and blood loss in total hip and knee arthroplasty: a prospective observational study. J Orthop Surg Res 2015;10:48. PMID: 25889413

13. Prasad N, Padmanabhan V, Mullaji A. Blood loss in total knee arthroplasty: an analysis of risk factors. Int Orthop 2007;31:39-44. PMID: 16568327

14. Salido JA, Marín LA, Gómez LA, Zorrilla P, Martínez C. Preoperative hemoglobin levels and the need for transfusion after prosthetic hip and knee surgery: analysis of predictive factors. J Bone Joint Surg Am 2002;84(2):216-220. PMID: 11861727

15. World Health Organization: Haemoglobin Concentrations for the Diagnosis of Anaemia and Assessment of Severity, WHO, Geneva, Switzerland, 2011. Available on: http://www.who.int/vmnis/indicators/haemoglobin/en/ [Accessed on $15^{\text {th }}$ December 2020]

16. Bierbaum BE, Callaghan JJ, Galante JO, Rubash HE, Tooms RE, Welch RB. An analysis of blood management in patients having a total hip or knee arthroplasty. J Bone Joint Surg Am 1999;81(1):210. PMID:9973048

17. Al-Turki AA, Al-Araifi AK, Badakhan BA, Al- Nazzawi MT, Alghnam S, Al-Turki AS. Predictors of blood transfusion following total knee replacement at a tertiary care center in Central Saudi Arabia. Saudi MedJ 2017;38(6):598-603. PMID: 28578438

18. Gerardo Alvarez-Uria, Praveen K.Naik, Manoranjan Midde, Pradeep S.Yalla and Raghavakalyan Pakam. Prevalence and Severity of Anaemia Stratified by Age and Gender in Rural India. Anemia, 2014:176182. DOI: http://doi.org/10.1155/2014/176182

19. Fabi DW, Mohan V, Goldstein WM, Dunn JH, Murphy BP.Unilateral vs Bilateral Total Knee Arthroplasty. Risk Factors Increasing Morbidity. The Journal of Arthroplasty 2011;26(5):668-673. PMID: 20875943

20. Holt JB, Miller BJ, Callaghan JJ, Clark CR, Willenborg MD, Noiseux NO. Minimizing Blood Transfusion in Total Hip and Knee Arthroplasty through a Multimodal Approach. J Arthroplasty 2016;31(2):378-382. PMID: 26391927

21. Moráis S, Ortega-Andreu M, Rodríguez-Merchán EC, PadillaEguiluz NG, Perez-Chrzanowska H, Figueredo-Zalve R, et al. Blood transfusion after primary total knee arthroplasty can be significantly minimized through a multimodal blood-loss prevention approach. International Orthopaedics (SICOT) 2014 38(2):347-354. PMID: 24318318

22. Frisch NB, Wessell NM, Charters MA, Yu S, Jeffries JJ, Silverton CD. Predictors and Complications of Blood Transfusion in Total Hip and Knee Arthroplasty. J Arthroplasty 2014;29(9 Suppl):189-192. PMID: 25007727

Publish your research articles with International Journal of Medical Sciences and Nursing Research Website: http://ijmsnr.com/ 